\title{
Magnesium and Nitrogen Co-Doped Mesoporous Carbon with Enhanced Microporosity for $\mathrm{CO}_{2}$ Adsorption
}

\author{
Jingting Lu ${ }^{1,2}$, Chengli Jiao ${ }^{1}$, Zeeshan Majeed ${ }^{1}$ and Heqing Jiang ${ }^{1, *}$ \\ 1 Qingdao Key Laboratory of Functional Membrane Material and Membrane Technology, Qingdao Institute of \\ Bioenergy and Bioprocess Technology, Chinese Academy of Sciences, No. 189 Songling Road, Qingdao \\ 266101, China; lujt@qibebt.ac.cn (J.L.); jiaocl@qibebt.ac.cn (C.J.); zeeshan@qibebt.ac.cn (Z.M.) \\ 2 University of Chinese Academy of Sciences, Beijing 100049, China \\ * Correspondence: jianghq@qibebt.ac.cn; Tel.: +86-532-80662716
}

Received: 29 March 2018; Accepted: 23 April 2018; Published: 25 April 2018

\begin{abstract}
Mesoporous carbons (MC) have attracted a tremendous amount of interest due to their efficient molecular transport properties. However, the limited number of active sites and low microporosity generally impede their use for practical applications. Herein, we have fabricated $\mathrm{Mg}$ and $\mathrm{N}$ co-doped mesoporous carbon (Mg-NMC) with high microporosity via one-pot synthetic route followed by further steam activation. In comparison with the parent N-doped mesoporous carbon, Mg-NMC shows partially ordered mesostructure and improved $\mathrm{CO}_{2}$ adsorption capacity attributed to the introduction of basic site after $\mathrm{Mg}$ doping. Upon further steam activation, the microporosity is enhanced to $37.3 \%$, while the $\mathrm{CO}_{2}$ adsorption capacity is also increased by $70.4 \%$ at $273 \mathrm{~K}$ and 1.0 bar.
\end{abstract}

Keywords: mesoporous carbon; Mg doping; steam activation; basic site; microporosity; $\mathrm{CO}_{2}$ adsorption

\section{Introduction}

Mesoporous carbons (pore size 2-50 nm) have attracted a great deal of attention in diverse areas including gas adsorption, catalysis and energy storage [1], owing to their unique physicochemical properties such as good chemical inertness and mesostructured channels. Compared to microporous carbon materials, the channels of mesoporous carbons facilitate fast mass transfer [2]. However, mesoporous carbon materials generally possess a limited number of active sites, which hinders their use for practical applications. Incorporation of heteroatoms such as B, N, P, S and F into carbon framework has been widely explored to increase the number of active sites of carbon materials [3-6]. In particular, the incorporation of $\mathrm{N}$ atoms not only increases number of basic sites but also improves surface polarity, which would significantly enhance the catalytic and adsorption properties of carbon materials [7]. For instance, Zhao et al. introduced $\mathrm{N}$ atoms into carbon framework to obtain N-doped mesoporous carbon with a high $\mathrm{N}$ content and a $\mathrm{CO}_{2}$ adsorption capacity of $2.8-3.2 \mathrm{mmol} \cdot \mathrm{g}^{-1}$ at $298 \mathrm{~K}$ and 1.0 bar [8]. However, most mesoporous carbons have a low $\mathrm{N}$ content or mesopore structure with low thermal stability [9], mainly due to the decomposition of N-containing precursors during self-assembly process and N-containing carbon framework during the carbonization at high temperature [8].

Recently, different metal species have been dispersed into N-containing carbon frameworks for improving adsorption and catalytic properties $[10,11]$. Some of these metal species may stabilize the preformed nitrogen sites [12]. In addition, previous literatures have suggested that $\mathrm{MgO}$ nanoparticles embedded into mesoporous carbon can provide a large number of basic $\mathrm{O}^{2-}$ sites which are beneficial 
for $\mathrm{CO}_{2}$ adsorption, and restrict further shrinkage of carbon framework $[13,14]$. On the other hand, $\mathrm{Mg}^{2+}$ can accelerate the polycondensation process, and improve the cure rate of phenolic resin [15].

In addition to basic active sites, microporosity is also one of the most important factors governing $\mathrm{CO}_{2}$ adsorption properties. It has been demonstrated that micropores with pore size less than $1 \mathrm{~nm}$ have strong adsorption affinity for $\mathrm{CO}_{2}$ molecules. Based on previous literature, microporosity of carbon materials can be easily enhanced by physical as well as chemical activation [16]. Currently, $\mathrm{KOH}$, $\mathrm{CO}_{2}, \mathrm{NH}_{3}$ and steam have been widely explored as common activation agents for the development of microporosity [17]. In contrast to other activation agents, steam has attracted intensive attention on account of being readily available, cost effective and environmentally benign. Han et al. reported that graphene aerogel with steam activation exhibited a higher $\mathrm{CO}_{2}$ adsorption capacity $\left(2.5 \mathrm{mmol} \cdot \mathrm{g}^{-1}\right.$ at $273 \mathrm{~K}$ and 1.0 bar) than sample without steam activation. In addition, the Langmuir specific surface area of graphene aerogel without steam activation was $820 \mathrm{~m}^{2} \cdot \mathrm{g}^{-1}$, which was increased to $1690 \mathrm{~m}^{2} \cdot \mathrm{g}^{-1}$ after steam treatment [18]. The enhanced surface area and $\mathrm{CO}_{2}$ adsorption performance were attributed to high microporosity resulting from steam activation.

The above discussion implies that the introduction of basic sites by doping heteroatoms or metal species coupled with enhanced microporosity by physicochemical activation play an important role in manipulating the adsorption properties of mesoporous carbon materials. However, the work reported so far mainly emphasized on how to increase the adsorption capacity either by tunable surface modification or adjustable microporosity. In this study, we combine these two strategies to enhance the $\mathrm{CO}_{2}$ adsorption properties of mesoporous carbon. At first, basic $\mathrm{N}$ and $\mathrm{Mg}$ species were incorporated into carbon framework using 3-aminophenol and hexamethylentetramine as nitrogen source and $\mathrm{Mg}\left(\mathrm{NO}_{3}\right)_{2} \cdot 6 \mathrm{H}_{2} \mathrm{O}$ as magnesium source, resulting in partially ordered mesostructure with two types of basic sites. In the second step, the as-synthesized $\mathrm{Mg}$ and $\mathrm{N}$ co-doped mesoporous carbon was etched by steam at elevated temperature to generate a large number of micropores in the carbon framework. As expected, after steam activation, the $\mathrm{Mg}$ and $\mathrm{N}$ co-doped material exhibited a much higher $\mathrm{CO}_{2}$ uptake capacity.

\section{Materials and Methods}

\subsection{Materials}

All chemicals were utilized as received without further purification: Pluronic F127 (Mw = 12,600 $\mathrm{EO}_{106}-\mathrm{PO}_{70}-\mathrm{EO}_{106}$, Sigma-Aldrich, Co., St. Louis, MO, USA), Magnesium nitrate hexahydrate (Sinopharm Chemical Regent Co., Ltd., Shanghai, China), 3-aminophenol (3-AP, Aladdin Industrial Corporation, Shanghai, China) and hexamethylentetramine (HMT, Aladdin Industrial Corporation, Shanghai, China).

\subsection{Synthesis of N-Containing Mesoporous Carbon and Mg and N Co-Doped Mesoporous Carbon}

$\mathrm{N}$-containing mesoporous carbon (NMC) and $\mathrm{Mg}$ and $\mathrm{N}$ co-doped mesoporous carbon (Mg-NMC) were prepared via a procedure similar to that reported by Wang et al. [19]. In a typical synthesis, $0.654 \mathrm{~g}$ of 3-AP, $0.42 \mathrm{~g}$ of HMT and $0.534 \mathrm{~g}$ of $\mathrm{Mg}\left(\mathrm{NO}_{3}\right)_{2} \cdot 6 \mathrm{H}_{2} \mathrm{O}$ were dissolved in $75 \mathrm{~mL}$ of deionized water at room temperature. Then, $5 \mathrm{~mL}$ of deionized water containing $0.47 \mathrm{~g}$ of Pluronic F127 was slowly added into the above solution with stirring. The resulting mixture was further stirred at room temperature for $30 \mathrm{~min}$ to obtain a homogeneous solution. After that, it was transferred to a thermostated oil bath to continue stirring at $50{ }^{\circ} \mathrm{C}$ for $16 \mathrm{~h}$, followed by stirring at $80^{\circ} \mathrm{C}$ for $8 \mathrm{~h}$ to ensure complete polymerization. The obtained polymer was collected by filtration, washed with deionized water and dried at $50{ }^{\circ} \mathrm{C}$ under vacuum. The dried sample was further calcined at $350{ }^{\circ} \mathrm{C}$ for $2 \mathrm{~h}$ followed by calcination at $700{ }^{\circ} \mathrm{C}$ for $3 \mathrm{~h}$ with a heating rate of $1{ }^{\circ} \mathrm{C} \mathrm{min}-1$ under argon flow. 


\subsection{Steam Activation}

Steam activation was performed in a quartz tube furnace, wherein $\mathrm{Mg}-\mathrm{NMC}$ was heated from room temperature to $700{ }^{\circ} \mathrm{C}$ at a ramp rate of $5{ }^{\circ} \mathrm{C} \mathrm{min}-1$ under a flow of argon. After the furnace temperature reached at $700{ }^{\circ} \mathrm{C}$, the carrier gas was bubbled through water before entering into the tube furnace and the furnace temperature was maintained at $700{ }^{\circ} \mathrm{C}$ for $4 \mathrm{~h}$. Finally, the carrier gas was switched back to pure argon in order to prevent uncontrolled activation during the cool down process. The final sample was denoted as $\mathrm{Mg}-\mathrm{NMC}-\mathrm{H}_{2} \mathrm{O}$.

\subsection{Characterization}

X-ray photoelectron spectroscopy (XPS) measurements were performed on an ESCALAB 250Xi with $\mathrm{Mg} \mathrm{K} \alpha$ (hv = $1253.6 \mathrm{eV})$ X-ray source (Thermo Fisher Scientific, Waltham, MA, USA). Fourier-transform infrared (FT-IR) spectra were recorded on a Nicolet iN10 IR microscope (Thermo Nicolet Corporation, Madison, WI, USA). Transmission electron microscopy (TEM) analyses were carried out using an H-7650 microscope (Hitachi High-Technologies Corporation, Tokyo, Japan) and a G2 microscope (FEI Co., Hillsboro, OR, USA) operated at an accelerate voltage of $120 \mathrm{kV}$. Nitrogen adsorption and desorption isotherms and $\mathrm{CO}_{2}$ adsorption isotherms were carried out on an Autosorb-iQ analyzer (Quantachrome Instruments, Boynton Beach, FL, USA ) at 77 K and 273 K, respectively. Prior to measurements, all samples were degassed under vacuum at $200{ }^{\circ} \mathrm{C}$ for $8 \mathrm{~h}$. Surface areas were calculated using Brunauer-Emmett-Teller (BET) method. Pore size distributions were calculated via the nonlocal density functional theory (NLDFT) algorithm. Microporosity was calculated from the relation $\mathrm{X} \%=\mathrm{V}_{\text {mico }} / \mathrm{V}_{\text {total }} \times 100 \%$. XRD patterns were obtained with a Bruker D8 Advance diffractometer (Bruker AXS GmbH, Karlsruhe, Germany) using Cu K $\alpha$ radiation source. Scanning electron microscopy (SEM) studies were conducted with Hitachi S-4800 microscopes (Hitachi, Tokyo, Japan). $\mathrm{CO}_{2}$ temperature programmed desorption $\left(\mathrm{CO}_{2}-\mathrm{TPD}\right)$ experiment was carried out on an AutoChem II 2920 chemisorption analyser (Micromeritics Instrument Corporation, Norcross, GA, USA). Before experiment, the sample was degassed at $700{ }^{\circ} \mathrm{C}$ for $2 \mathrm{~h}$ under helium flow, and then cooled down to room temperature. The sample was exposed to flowing $10 \% \mathrm{CO}_{2} / \mathrm{He}$ for $2 \mathrm{~h}$, and heated from room temperature to $900{ }^{\circ} \mathrm{C}$ under helium flow with a heating rate of $10{ }^{\circ} \mathrm{C} \mathrm{min}{ }^{-1}$.

\section{Results and Discussion}

NMC was fabricated via soft-template method using 3-AP and HMT as precursors and F127 as surfactant under alkaline conditions. Addition of magnesium salt into the precursors of NMC produced $\mathrm{Mg}-\mathrm{NMC}$. The sample $\mathrm{Mg}-\mathrm{NMC}-\mathrm{H}_{2} \mathrm{O}$ was obtained by further etching of $\mathrm{Mg}-\mathrm{NMC}$ in water vapor at elevated temperature. XPS analyses were performed to investigate the chemical composition of all the samples. As shown in Figure 1a, the XPS spectra of NMC and Mg-NMC exhibit strong signals of carbon, nitrogen and oxygen elements, verifying the presence of $\mathrm{N}$ in the two samples. The N content of NMC reaches up to $10.9 \mathrm{wt} \%$, which is higher than the value reported in previous literature. Additionally, the XPS spectrum of Mg-NMC shows Mg 1s signal, indicating a successful incorporation of $\mathrm{Mg}$ within the mesoporous matrix. In order to investigate the types of nitrogen species present in NMC before and after Mg doping, $\mathrm{N}$ 1s XPS analysis was performed and the corresponding spectra are presented in Figure $1 \mathrm{~b}$. Three peaks are observed in the $\mathrm{N} 1 \mathrm{~s}$ curve-fitting spectrum of NMC. The peak at $398.3 \mathrm{eV}$ is assigned to pyridinic $\mathrm{N}$, the strong peak at $400.6 \mathrm{eV}$ is attributed to pyrrolic $\mathrm{N}$, while the small peak at $403.2 \mathrm{eV}$ can be ascribed to oxidized pyridinic $\mathrm{N}[20,21]$. After Mg doping, the $\mathrm{N}$ 1s spectrum shows a new peak at $400.8 \mathrm{eV}$ which is attributed to graphitic N [2]. Therefore, it can be reasonably speculated that $\mathrm{Mg}$ doping leads to the generation of graphitic $\mathrm{N}$ sites in carbon framework. Both pyridinic and graphitic $\mathrm{N}$ are considered as basic sites [22,23]. Magnesium and oxygen states of Mg-NMC before and after steam activation were investigated in detail. As shown in Figure 1c, Mg 1s XPS spectrum of Mg-NMC consists of two peaks located at 1304.4 and $1304.7 \mathrm{eV}$ which indicate the presence of $\mathrm{MgO}$ and $\mathrm{MgCO}_{3}$ [24,25]. This can 
be explained on the following grounds. Initially, $\mathrm{Mg}\left(\mathrm{NO}_{3}\right)_{2}$ fully decomposed to $\mathrm{MgO}$ during the calcination of $\mathrm{Mg}-\mathrm{NMC}$ at $700^{\circ} \mathrm{C} . \mathrm{MgO}$ probably converted to $\mathrm{MgCO}_{3}$ and $\mathrm{Mg}(\mathrm{OH})_{2}$ in situ by reaction with $\mathrm{CO}_{2}$ and water released from the carbonization of phenolic resin and decomposition of triblock copolymer [26]. Subsequently, these Mg species could decompose either partially or completely back to $\mathrm{MgO}$ under high temperature conditions. Apart from $\mathrm{MgCO}_{3}$, a small amount of $\mathrm{Mg}(\mathrm{OH})_{2}$ might also be present, but it is difficult to observe due to the low peak intensity [27]. After steam activation, three peaks were observed at 1303.9, 1304.7 and $1305 \mathrm{eV}$ respectively in the $\mathrm{Mg}$ 1s spectrum of $\mathrm{Mg}-\mathrm{NMC}-\mathrm{H}_{2} \mathrm{O}$ (Figure 1c, upper). The peak at $1303.9 \mathrm{eV}$ indicates the presence of $\mathrm{Mg}(\mathrm{OH})_{2}$, which is probably formed by the reaction between $\mathrm{MgO} / \mathrm{MgCO}_{3}$ and adsorbed water during the steam activation process [28]. Figure $1 \mathrm{~d}$ displays the $\mathrm{O} 1 \mathrm{~s}$ XPS spectra of $\mathrm{Mg}-\mathrm{NMC}$ and $\mathrm{Mg}-\mathrm{NMC}-\mathrm{H}_{2} \mathrm{O}$. Before steam activation, the $\mathrm{O} 1 \mathrm{~s}$ curve-fitting spectrum of Mg-NMC contains three peaks located at $530.9 \mathrm{eV}(\mathrm{MgO}) ; 531.9 \mathrm{eV}$ (C-O); and $533.0 \mathrm{eV}\left(\mathrm{MgCO}_{3}\right)$ [29-31]. In contrast, after steam activation, central peak shifts from 531.9 to $532.1 \mathrm{eV}$, which can be ascribed to the combination of $\mathrm{C}-\mathrm{O}$ and $\mathrm{Mg}(\mathrm{OH})_{2}$ [29]. These results suggest that $\mathrm{Mg}-\mathrm{NMC}-\mathrm{H}_{2} \mathrm{O}$ probably contains $\mathrm{MgO}, \mathrm{MgCO}_{3}$ and $\mathrm{Mg}(\mathrm{OH})_{2}$. However, it is difficult to ascertain these magnesium species by XPS analysis, which can be further confirmed by FT-IR measurement.
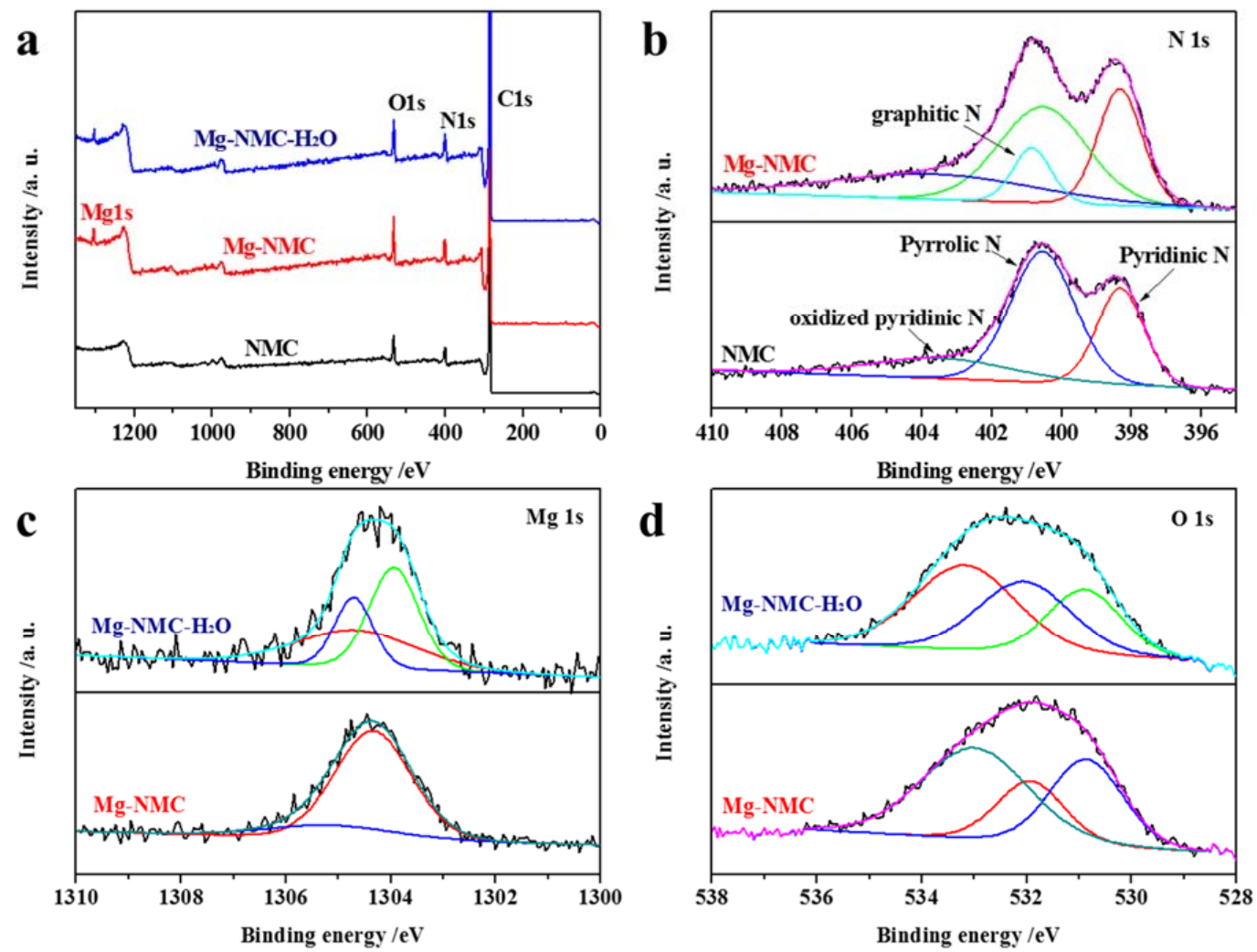

Figure 1. (a) XPS survey spectra for NMC, Mg-NMC and Mg-NMC- $\mathrm{H}_{2} \mathrm{O}$; (b) XPS N 1s spectra of NMC and $\mathrm{Mg}-\mathrm{NMC}$; (c) XPS Mg 1s and (d) $\mathrm{O}$ 1s spectra of Mg-NMC and Mg-NMC- $\mathrm{H}_{2} \mathrm{O}$.

The FT-IR spectra of NMC, Mg-NMC and Mg-NMC- $\mathrm{H}_{2} \mathrm{O}$ are depicted in Figure 2. As shown in Figure 2a, the featured absorption peaks assigned to N-containing carbons are observed for NMC, such as $3446 \mathrm{~cm}^{-1}$ (N-H stretching vibration), $1628 \mathrm{~cm}^{-1}$ (C=C and $\mathrm{C}=\mathrm{O}$ stretching vibration) and $1100 \mathrm{~cm}^{-1}$ (C-N or C-O stretching vibration) [32-34]. These results further confirm the existence of nitrogen species in NMC. After incorporation of Mg into the NMC framework (Figure 2b), two absorption peaks in the finger print region at 668 and $596 \mathrm{~cm}^{-1}$ can be assigned to $\mathrm{Mg}$-O stretching and bending vibrations, suggesting the formation of $\mathrm{MgO}$ in $\mathrm{Mg}-\mathrm{NMC}[35,36]$. In addition, the absorption peak at $856 \mathrm{~cm}^{-1}$ is ascribed to the out-of-plane bending vibrations of $\mathrm{CO}_{3}{ }^{2-}$ [37]. After steam activation, a new observed peak at $449 \mathrm{~cm}^{-1}$ can be assigned to $\mathrm{Mg}-\mathrm{O}$ stretching vibration in $\mathrm{Mg}(\mathrm{OH})_{2}$ [38]. All these results 
demonstrate that $\mathrm{MgO}$ and $\mathrm{MgCO}_{3}$ co-exist in $\mathrm{Mg}-\mathrm{NMC}$, whereas after steam activation $\mathrm{Mg}(\mathrm{OH})_{2}$ is generated in the framework of $\mathrm{Mg}-\mathrm{NMC}-\mathrm{H}_{2} \mathrm{O}$.
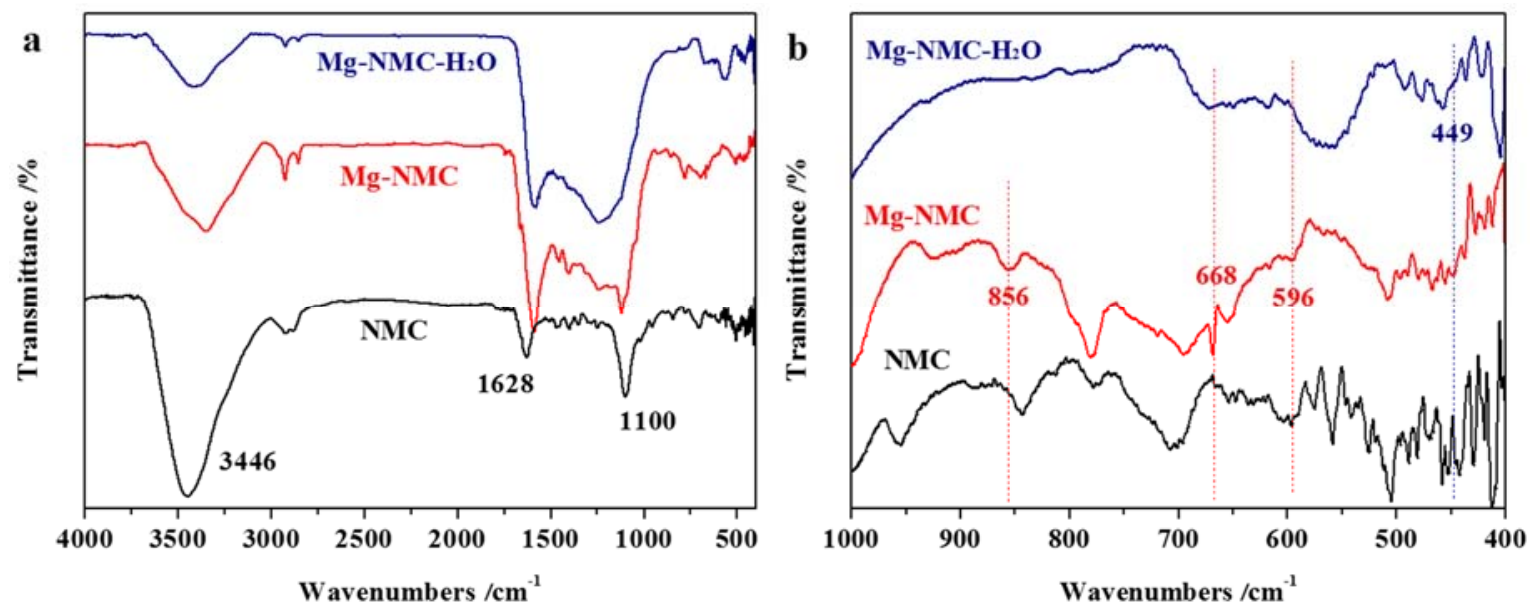

Figure 2. FT-IR spectra (a,b) of NMC, Mg-NMC and $\mathrm{Mg}-\mathrm{NMC}-\mathrm{H}_{2} \mathrm{O}$.
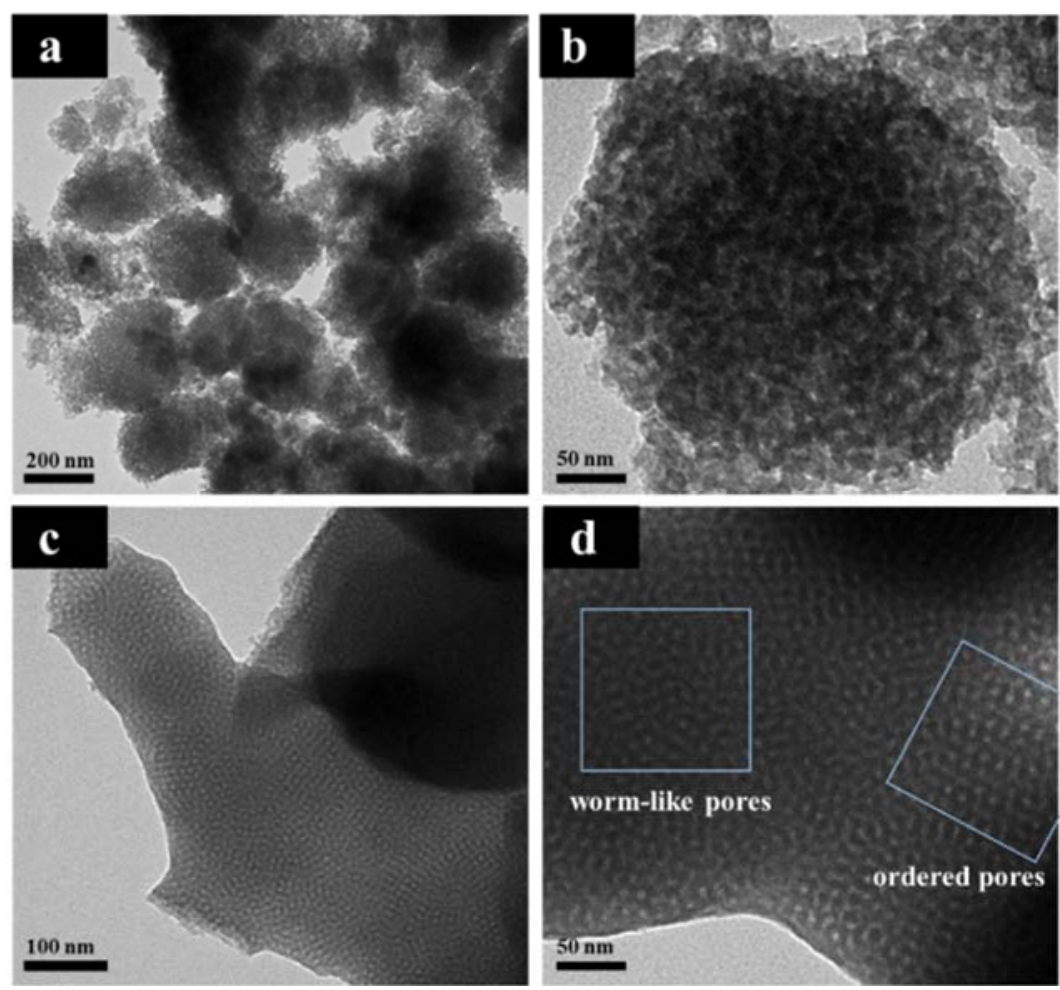

Figure 3. TEM images of NMC (a,b) and $\mathrm{Mg}-\mathrm{NMC}(\mathbf{c}, \mathbf{d})$.

In order to further probe the influence of $\mathrm{Mg}$ doping on the morphology and mesostructure of NMC, TEM analyses were performed. As shown in Figure 3a and b, the parent NMC exhibits spherical morphology with a disordered mesostructure. However, after $\mathrm{Mg}$ doping the sample Mg-NMC shows a combination of ordered and worm-like mesostructure (Figure 3c,d). This enhanced mesostructure ordering is mainly attributed to $\mathrm{Mg}$ doping. During the self-assembly process, $\mathrm{Mg}^{2+}$ can improve the polymerization of ortho-methylol groups to generate methylene linkages, leaving more para-methylol groups which can easily react with similar groups from other molecules resulting in considerable shortening of cure time of the resin [39]. Previous reports have also suggested that 
enhancing polymerization [40] or polycondensation [41] rate contributes towards improvement of structural ordering. As seen in Figure 3, the disordered mesostructure is changed to partially ordered mesostructure after $\mathrm{Mg}$ doping, indicating the efficacy of $\mathrm{Mg}^{2+}$ as a catalyst for the construction of ordered mesostructure. Furthermore, no isolated particles are observed either outside or on the surface of Mg-NMC matrix (Figure 3c,d), which probably refers to a high dispersion of $\mathrm{MgO}$ and $/$ or $\mathrm{MgCO}_{3}$ within the mesoporous framework without any microphase separation.

The wide-angle XRD pattern of Mg-NMC presents no apparent diffraction peaks of $\mathrm{MgO}$ and $\mathrm{MgCO}_{3}$ (Figure 4a), suggesting small particle size as well as high dispersion of magnesium species within the Mg-NMC matrix. Small-angle XRD patterns of NMC and Mg-NMC are displayed in Figure $4 \mathrm{~b}$. There is no peak in the small-angle XRD pattern of NMC, indicating its disordered mesostructure. In contrast, a strong diffraction peak around $0.94^{\circ}$ is observed for $\mathrm{Mg}-\mathrm{NMC}$, which implies that ordered mesostructure can be obtained by the addition of $\mathrm{Mg}\left(\mathrm{NO}_{3}\right)_{2}$. These results are in good agreement with the TEM results.
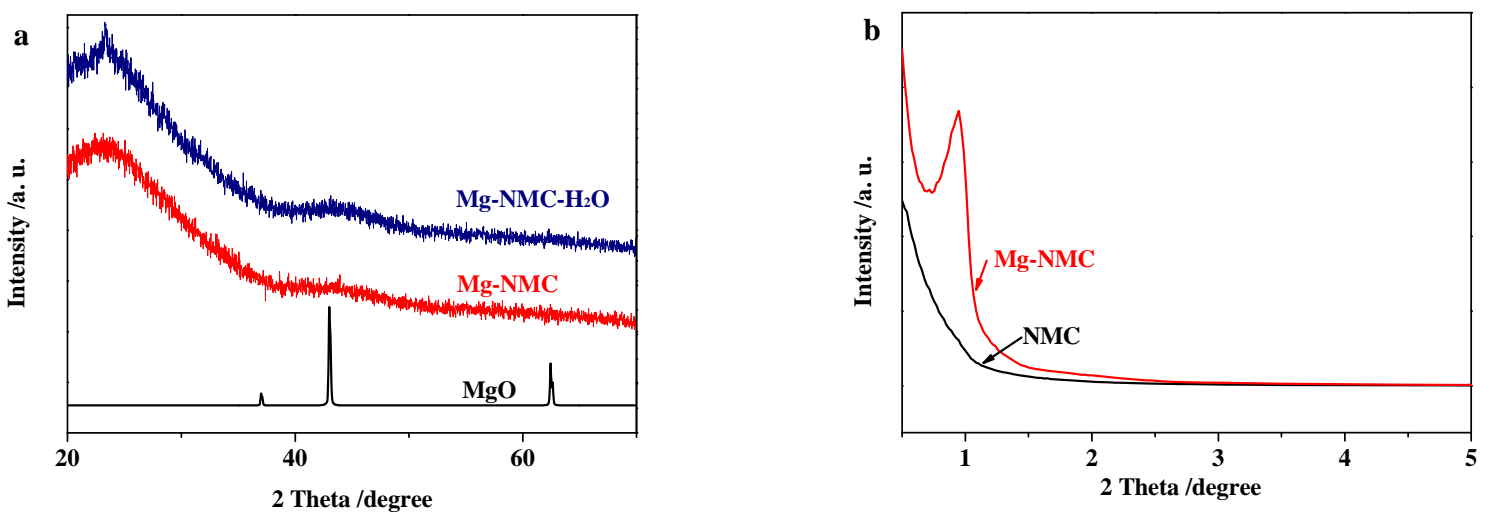

Figure 4. (a) Wide-angle XRD patterns of $\mathrm{MgO}$, $\mathrm{Mg}-\mathrm{NMC}$ and $\mathrm{Mg}-\mathrm{NMC}-\mathrm{H}_{2} \mathrm{O}$; (b) Small-angle XRD patterns of NMC and Mg-NMC.

Effect of $\mathrm{Mg}$ doping and steam activation on textural features such as microporosity and specific surface area was deeply investigated by $\mathrm{N}_{2}$ adsorption measurements. Figure 5 displays the $\mathrm{N}_{2}$ sorption isotherms and pore size distribution plots of NMC, Mg-NMC and Mg-NMC- ${ }_{2} \mathrm{O}$. Both NMC and Mg-NMC exhibit typical type IV adsorption curves. However, there are some differences in the shapes of hysteresis loops. The sample NMC displays a typical $\mathrm{H}_{1}$-type hysteresis loop and a sharp capillary condensation at high relative pressure range $\left(\mathrm{P} / \mathrm{P}_{\mathrm{o}}>0.5\right)$. In contrast, $\mathrm{Mg}-\mathrm{NMC}$ exhibits an $\mathrm{H}_{2}$-type hysteresis loop and an adsorption saturation platform at a relative pressure of about 0.5 . This indicates the improvement of mesostructure ordering for Mg-NMC, which further validates the TEM and small-angle XRD results. Moreover, the pore size of NMC decreases from 9 to $4.5 \mathrm{~nm}$ after $\mathrm{Mg}$ doping (Figure 5b). A comparison of the textural properties of NMC, $\mathrm{Mg}-\mathrm{NMC}$ and $\mathrm{Mg}-\mathrm{NMC}-\mathrm{H}_{2} \mathrm{O}$ is given in Table 1 . The specific surface area of NMC reduces from 457 to $385 \mathrm{~m}^{2} \cdot \mathrm{g}^{-1}$. However, the microporosity of NMC increases from $18.3 \%$ to $29.8 \%$. These results indicate that $\mathrm{Mg}$ doping has a profound influence on the formation of mesostructure during the synthesis process.

Table 1. Textural properties of NMC, Mg-NMC and $\mathrm{Mg}-\mathrm{NMC}-\mathrm{H}_{2} \mathrm{O}$.

\begin{tabular}{|c|c|c|c|c|c|}
\hline Sample & $\mathrm{S}_{\mathrm{BET}} / \mathrm{m}^{2} \cdot \mathrm{g}^{-1}$ & $\mathrm{~V}_{\text {total }} / \mathrm{cm}^{3} \cdot \mathrm{g}^{-1}$ & $\mathrm{~V}_{\text {micro }} / \mathrm{cm}^{3} \cdot \mathrm{g}^{-1}$ & $\mathrm{~V}_{\text {meso }} / \mathrm{cm}^{3} \cdot \mathrm{g}^{-1}$ & Microporosity/\% \\
\hline NMC & 457 & 0.58 & 0.106 & 0.476 & 18.3 \\
\hline $\mathrm{Mg}-\mathrm{NMC}$ & 385 & 0.30 & 0.088 & 0.212 & 29.8 \\
\hline $\mathrm{Mg}-\mathrm{NMC}-\mathrm{H}_{2} \mathrm{O}$ & 541 & 0.36 & 0.136 & 0.224 & 37.3 \\
\hline
\end{tabular}



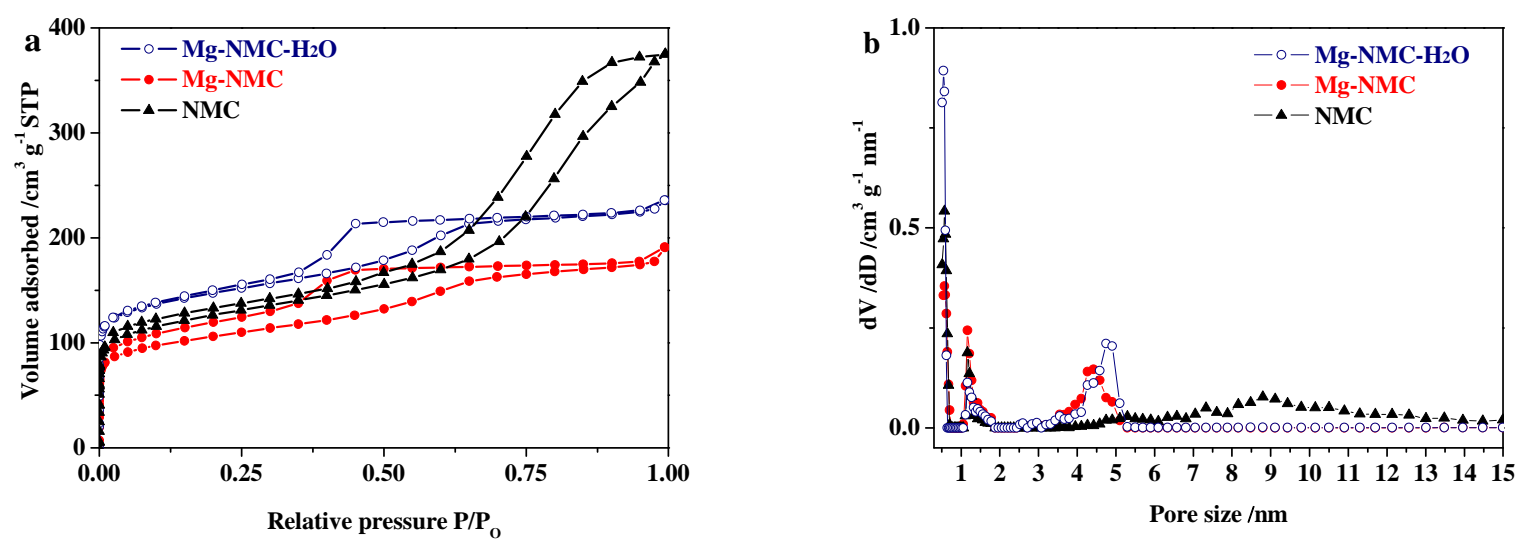

Figure 5. $\mathrm{N}_{2}$ sorption isotherms (a) and pore size distribution plots (b) of NMC (solid triangles), $\mathrm{Mg}-\mathrm{NMC}$ (solid circles) and $\mathrm{Mg}-\mathrm{NMC}-\mathrm{H}_{2} \mathrm{O}$ (open circles).

After steam activation, $\mathrm{Mg}-\mathrm{NMC}-\mathrm{H}_{2} \mathrm{O}$ exhibits a much sharper slope at the low relative pressure region (Figure 5a). This phenomenon is due to additional micropores generated by steam etching of $\mathrm{Mg}$ and $\mathrm{N}$ co-doped carbon framework. During the steam activation process, steam acts as an oxidizing agent for carbon, with a concomitant release of $\mathrm{H}_{2}$ and $\mathrm{CO}$ which results in the formation of additional micropores. Compared to Mg-NMC, the increased microporosity (from 29.8\% to 37.3\%) and higher specific surface area (from 385 to $541 \mathrm{~m}^{2} \cdot \mathrm{g}^{-1}$ ) for $\mathrm{Mg}-\mathrm{NMC}-\mathrm{H}_{2} \mathrm{O}$ are mainly attributed to these additional micropores. As shown in Figure 5b, the number of micropores with pore size around $0.55 \mathrm{~nm}$ significantly increases after steam activation, implying that steam activation can generate more micoropores (below $1 \mathrm{~nm}$ ). Indeed, it is well known that high microporosity is beneficial for carbon materials to adsorb gas molecules.

The $\mathrm{CO}_{2}$ adsorption capacities of $\mathrm{NMC}, \mathrm{Mg}-\mathrm{NMC}$ and $\mathrm{Mg}-\mathrm{NMC}-\mathrm{H}_{2} \mathrm{O}$ were investigated at $273 \mathrm{~K}$ and corresponding adsorption isotherms are depicted in Figure $6 \mathrm{a}$, while Figure $6 \mathrm{~b}$ displays the $\mathrm{CO}_{2}$-TPD profile of Mg-NMC. As can be seen in Figure 6a, before Mg doping, NMC shows an adsorption capacity of $2.16 \mathrm{mmol} \cdot \mathrm{g}^{-1}$ at $1.0 \mathrm{bar}$, which increases to $2.77 \mathrm{mmol} \cdot \mathrm{g}^{-1}$ after incorporation of $\mathrm{Mg}$ species into the carbon matrix. Upon steam activation, the adsorption capacity is further enhanced and reaches up to $3.68 \mathrm{mmol} \cdot \mathrm{g}^{-1}$ at $1.0 \mathrm{bar}$, which is much higher compared to the inactivated sample. In general, the $\mathrm{CO}_{2}$ adsorption capacity of a mesoporous material can be improved by the introduction of basic active sites as well as enhanced microporosity. According to the XPS results previously discussed, $\mathrm{Mg}$ doping leads to the generation of basic graphitic $\mathrm{N}$ sites in addition to pyridinic and pyrrolic $\mathrm{N}$ sites inside the carbon matrix. In addition, the $\mathrm{CO}_{2}$-TPD profile of Mg-NMC (Figure $6 \mathrm{~b}$ ) presents two distinct desorption peaks corresponding to two different types of basic sites i.e., $\mathrm{N}$ [42] and $\mathrm{O}^{2-}$ [43]. In addition, $\mathrm{Mg}-\mathrm{NMC}$ also possesses higher microporosity $(29.8 \%)$ compared to NMC $(18.3 \%)$ as given in Table 1 . These results account for the improved $\mathrm{CO}_{2}$ uptake capacity of $\mathrm{Mg}-\mathrm{NMC}$ over NMC. Subsequently, steam activation not only increases the microporosity and specific surface area of Mg-NMC, but also exposes more basic sites to the gas molecules, thereby leading to a further enhancement of $\mathrm{CO}_{2}$ uptake capacity. In addition, it is known that suitable micropores with pore size $<1 \mathrm{~nm}$ have strong adsorption affinity for $\mathrm{CO}_{2}$ molecules. For example, Jaroniec et al. have reported that high micropore volume with small pore size (typically less than $0.8 \mathrm{~nm}$ ) is essential for enhancing $\mathrm{CO}_{2}$ adsorption capacity [44]. Likewise in our case, the enhanced adsorption capacity can also be partly attributed to increased microporosity owing to the micropores with pore size around $0.55 \mathrm{~nm}$ for $\mathrm{Mg}-\mathrm{NMC}-\mathrm{H}_{2} \mathrm{O}$ (Figure 5b). As a result, after Mg doping followed by steam activation, the $\mathrm{CO}_{2}$ adsorption capacity of NMC increases by $70.4 \%$, implying that basic active sites and microporosity are significantly important for improving the adsorptive performance of mesoporous carbon materials. 

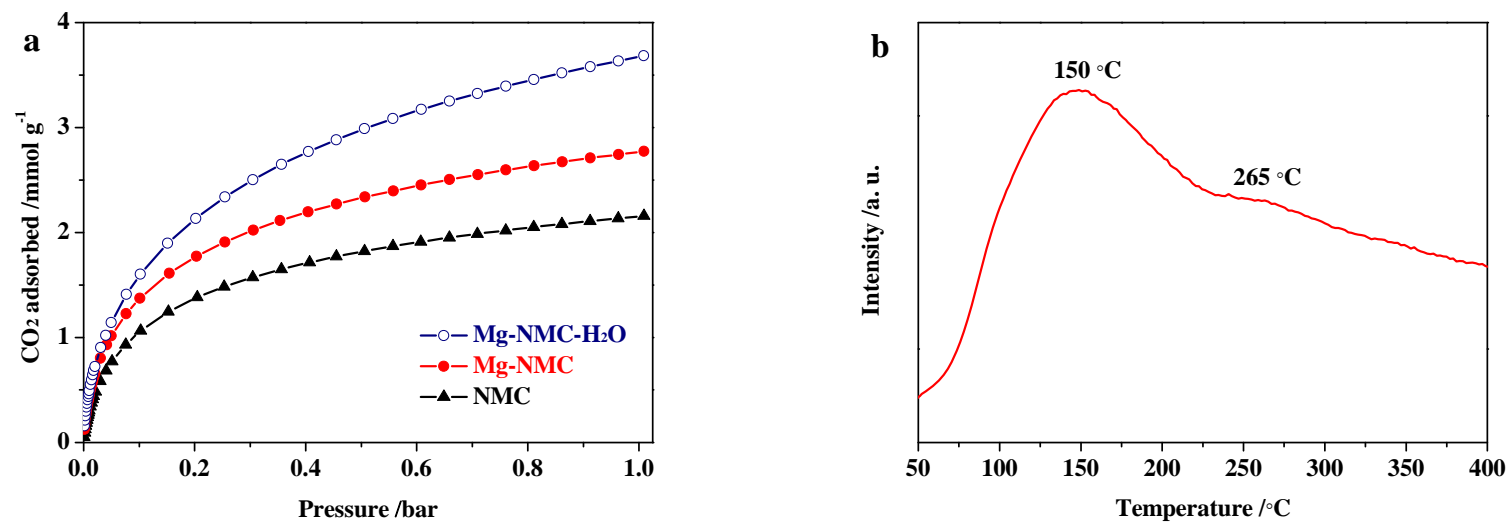

Figure 6. (a) $\mathrm{CO}_{2}$ adsorption isotherms for $\mathrm{NMC}, \mathrm{Mg}-\mathrm{NMC}$ and $\mathrm{Mg}-\mathrm{NMC}-\mathrm{H}_{2} \mathrm{O}$ at $273 \mathrm{~K}$; (b) $\mathrm{CO}_{2}-\mathrm{TPD}$ profile of Mg-NMC.

\section{Conclusions}

In summary, $\mathrm{Mg}$ and $\mathrm{N}$ co-doped mesoporous carbon with high microporosity was successfully prepared via one-pot self-assembly method followed by steam activation. In contrast to $\mathrm{N}$-doped mesoporous carbon, $\mathrm{Mg}$ and $\mathrm{N}$ co-doped mesoporous carbon showed two types of basic sites and partially ordered mesostructure. Upon further steam activation, the microporosity was enhanced to $37.3 \%$, while the specific surface area was increased from 385 to $541 \mathrm{~m}^{2} \cdot \mathrm{g}^{-1}$. Moreover, the $\mathrm{Mg}$ and $\mathrm{N}$ co-doped mesoporous carbon exhibited a good $\mathrm{CO}_{2}$ adsorption capacity of $3.68 \mathrm{mmol} \cdot \mathrm{g}^{-1}$ at $273 \mathrm{~K}$ and 1.0 bar. The present strategy paves the way towards synthesizing heteroatom and metal oxide co-doped mesoporous carbons with high porosity for potential applications in gas adsorption and catalysis.

Author Contributions: Heqing Jiang and Chengli Jiao designed the experiments and revised the paper; Jingting Lu performed the experiments, analyzed the data and wrote the paper; Zeeshan Majeed wrote the paper.

Acknowledgments: The authors acknowledge the financial support from the National Natural Science Foundation of China (21403267 and 21650110459), Qingdao Applied Basic Research Projects (17-1-1-75-jch), and CAS President's International Fellowship Initiative (2016PT015).

Conflicts of Interest: There are no conflicts of interest to declare.

\section{References}

1. Liang, C.D.; Li, Z.J.; Dai, S. Mesoporous carbon materials: Synthesis and modification. Angew. Chem. Int. Ed. 2008, 47, 3696-3717.

2. Tang, J.; Liu, J.; Li, C.L.; Li, Y.Q.; Tade, M.O.; Dai, S.; Yamauchi, Y. Synthesis of nitrogen-doped mesoporous carbon spheres with extra-large pores through assembly of diblock copolymer micelles. Angew. Chem. Int. Ed. 2015, 54, 588-593. [CrossRef]

3. Asefa, T. Metal-free and noble metal-free heteroatom-doped nanostructured carbons as prospective sustainable electrocatalysts. Acc. Chem. Res. 2016, 49, 1873-1883. [CrossRef] [PubMed]

4. Shahtalebi, A.; Mar, M.; Guérin, K.; Bhatia, S.K. Effect of fluorine doping on structure and $\mathrm{CO}_{2}$ adsorption in silicon carbide-derived carbon. Carbon 2016, 96, 565-577. [CrossRef]

5. Nabae, Y.; Nagata, S.; Ohnishi, K.; Liu, Y.Y.; Sheng, L.; Wang, X.L.; Hayakawa, T. Block copolymer templated carbonization of nitrogen containing polymer to create fine and mesoporous carbon for oxygen reduction catalyst. J. Polym. Sci. Polym. Chem. 2017, 55, 464-470. [CrossRef]

6. Liu, Y.Y.; Ohnishi, K.; Sugimoto, S.; Okuhara, K.; Maeda, R.; Nabae, Y.; Kakimoto, M.; Wang, X.L.; Hayakawa, T. Well-ordered mesoporous polymers and carbons based on imide-incorporated soft materials. Polym. Chem. 2014, 5, 6452-6460. [CrossRef] 
7. Yu, J.; Guo, M.Y.; Muhammad, F.; Wang, A.F.; Zhang, F.; Li, Q.; Zhu, G.S. One-pot synthesis of highly ordered nitrogen-containing mesoporous carbon with resorcinol-urea-formaldehyde resin for $\mathrm{CO}_{2}$ capture. Carbon 2014, 69, 502-514. [CrossRef]

8. Wei, J.; Zhou, D.D.; Sun, Z.K.; Deng, Y.H.; Xia, Y.Y.; Zhao, D.Y. A controllable synthesis of rich nitrogen-doped ordered mesoporous carbon for $\mathrm{CO}_{2}$ capture and supercapacitors. Adv. Funct. Mater. 2013, 23, 2322-2328. [CrossRef]

9. Yang, J.P.; Zhai, Y.P.; Deng, Y.H.; Gu, D.; Li, Q.; Wu, Q.L.; Huang, Y.; Tu, B.; Zhao, D.Y. Direct triblock-copolymer-templating synthesis of ordered nitrogen-containing mesoporous polymers. J. Colloid Interface Sci. 2010, 342, 579-585. [CrossRef] [PubMed]

10. Zhang, Z.Z.; Zhu, C.M.; Sun, N.N.; Wang, H.; Tang, Z.Y.; Wei, W.; Sun, Y.H. One-pot solvent-free synthesis of nitrogen and magnesium codoped mesoporous carbon composites for $\mathrm{CO}_{2}$ Capture. J. Phys. Chem. C 2015, 119, 9302-9310. [CrossRef]

11. Wang, G.H.; Deng, X.H.; Gu, D.; Chen, K.; Tüysüz, H.; Spliethoff, B.; Bongard, H.J.; Weidenthaler, C.; Schmidt, W.; Schüth, F. $\mathrm{CO}_{3} \mathrm{O}_{4}$ nanoparticles supported on mesoporous carbon for selective transfer hydrogenation of $\alpha, \beta$-unsaturated aldehydes. Angew. Chem. Int. Ed. 2016, 55, 11267-11271. [CrossRef]

12. Wang, X.Q.; Lee, J.S.; Zhu, Q.; Liu, J.; Wang, Y.; Dai, S. Ammonia-treated ordered mesoporous carbons as catalytic materials for oxygen reduction reaction. Chem. Mater. 2010, 22, 2178-2180. [CrossRef]

13. Liu, W.J.; Jiang, H.; Tian, K.; Ding, Y.W.; Yu, H.Q. Mesoporous carbon stabilized MgO nanoparticles synthesized by pyrolysis of $\mathrm{MgCl}_{2}$ preloaded waste biomass for highly efficient $\mathrm{CO}_{2}$ capture. Environ. Sci. Technol. 2013, 47, 9397-9403. [CrossRef] [PubMed]

14. She, L.; Li, J.; Wan, Y.; Yao, X.D.; Tu, B.; Zhao, D.Y. Synthesis of ordered mesoporous MgO/carbon composites by a one-pot assembly of amphiphilic triblock copolymers. J. Mater. Chem. 2011, 21, 795-800. [CrossRef]

15. Fan, D.B.; Li, G.Y.; Qin, T.F.; Chu, F.X. Synthesis and structure characterization of phenol-urea-formaldehyde resins in the presence of magnesium oxide as catalyst. Polymers 2014, 6, 2221-2231. [CrossRef]

16. Górka, J.; Jaroniec, M. Hierarchically porous phenolic resin-based carbons obtained by block copolymer-colloidal silica templating and post-synthesis activation with carbon dioxide and water vapor. Carbon 2011, 49, 154-160. [CrossRef]

17. Ludwinowicz, J.; Jaroniec, M. Effect of activating agents on the development of microporosity in polymeric-based carbon for $\mathrm{CO}_{2}$ adsorption. Carbon 2015, 94, 673-679. [CrossRef]

18. Sui, Z.Y.; Meng, Q.H.; Li, J.T.; Zhu, J.H.; Cui, Y.; Han, B.H. High surface area porous carbons produced by steam activation of graphene aerogels. J. Mater. Chem. A 2014, 2, 9891-9898. [CrossRef]

19. Wang, G.H.; Cao, Z.W.; Gu, D.; Pfänder, N.; Swertz, A.-C.; Spliethoff, B.; Bongard, H.-J.; Weidenthaler, C.; Schmidt, W.; Rinaldi, R.; et al. Nitrogen-doped ordered mesoporous carbon supported bimetallic PtCo nanoparticles for upgrading of biophenolics. Angew. Chem. Int. Ed. 2016, 55, 8850-8855. [CrossRef] [PubMed]

20. Daems, N.; Sheng, X.; Vankelecom, I.F.J.; Pescarmona, P.P. Metal-free doped carbon materials as electrocatalysts for the oxygen reduction reaction. J. Mater. Chem. A 2014, 2, 4085-4110. [CrossRef]

21. Xu, Q.; Yu, X.L.; Liang, Q.H.; Bai, Y.; Huang, Z.H.; Kang, F.Y. Nitrogen-doped hollow activated carbon nanofibers as high performance supercapacitor electrodes. J. Electroanal. Chem. 2015, 739, 84-88. [CrossRef]

22. Guo, D.H.; Shibuya, R.; Akiba, C.; Saji, S.; Kondo, T.; Nakamura, J. Active sites of nitrogen-doped carbon materials for oxygen reduction reaction clarified using model catalysts. Science 2016, 351, 361-365. [CrossRef] [PubMed]

23. Zhou, M.; Wang, H.L.; Guo, S.J. Towards high-efficiency nanoelectrocatalysts for oxygen reduction through engineering advanced carbon nanomaterials. Chem. Soc. Rev. 2016, 45, 1273-1307. [CrossRef] [PubMed]

24. Ohtani, S.; Yano, T.; Kondo, S.; Kohno, Y.; Tomita, Y.; Maeda, Y.; Kobayashi, K. Electron emission from h-BN films codoped with Mg and $\mathrm{O}$ atoms. Thin Solid Films 2013, 546, 53-57. [CrossRef]

25. Khairallah, F.; Glisenti, A. Synthesis, characterization and reactivity study of nanoscale magnesium oxide. J. Mol. Catal. A Chem. 2007, 274, 137-147. [CrossRef]

26. Wu, Z.X.; Meng, Y.; Zhao, D.Y. Nanocasting fabrication of ordered mesoporous phenol-formaldehyde resins with various structures and their adsorption performances for basic organic compounds. Microporous Mesoporous Mat. 2010, 128, 165-179. [CrossRef]

27. Wu, Z.X.; Hao, N.; Xiao, G.K.; Liu, L.Y.; Webley, P.; Zhao, D.Y. One-pot generation of mesoporous carbon supported nanocrystalline calcium oxides capable of efficient $\mathrm{CO}_{2}$ capture over a wide range of temperatures. Phys. Chem. Chem. Phys. 2011, 13, 2495-2503. [CrossRef] [PubMed] 
28. Neville, A.; Morizot, A.P. Calcareous scales formed by cathodic protection-an assessment of characteristics and kinetics. J. Cryst. Growth 2002, 243, 490-502. [CrossRef]

29. Zhang, H.; Luo, R.F.; Li, W.J.; Wang, J.; Maitz, M.F.; Wang, J.; Wan, G.J.; Chen, Y.Q.; Sun, H.; Jiang, C.X.; et al. Epigallocatechin gallate (EGCG) induced chemical conversion coatings for corrosion protection of biomedical MgZnMn alloys. Corros. Sci. 2015, 94, 305-315. [CrossRef]

30. Liu, S.; Tian, J.Q.; Wang, L.; Zhang, Y.W.; Qin, X.Y.; Luo, Y.L.; Asiri, A.M.; Al-Youbi, A.O.; Sun, X.P. Hydrothermal treatment of grass: A low-cost, green route to nitrogen-doped, carbon-rich, photoluminescent polymer nanodots as an effective fluorescent sensing platform for label-free detection of $\mathrm{Cu}(\mathrm{II})$ ions. Adv. Mater. 2012, 24, 2037-2041. [CrossRef] [PubMed]

31. Santamaria, M.; Quarto, F.D.; Zanna, S.; Marcus, P. Initial surface film on magnesium metal: A characterization by X-ray photoelectron spectroscopy (XPS) and photocurrent spectroscopy (PCS). Electrochim. Acta 2007, 53, 1314-1324. [CrossRef]

32. Tseng, R.-L.; Wu, F.-C.; Juang, R.-S. Adsorption of $\mathrm{CO}_{2}$ at atmospheric pressure on activated carbons prepared from melamine-modified phenol-formaldehyde resins. Sep. Purif. Technol. 2015, 140, 53-60. [CrossRef]

33. Li, Y.B.; Zhang, H.M.; Wang, Y.; Liu, P.R.; Yang, H.G.; Yao, X.D.; Wang, D.; Tang, Z.Y.; Zhao, H.J. A self-sponsored doping approach for controllable synthesis of $\mathrm{S}$ and $\mathrm{N}$ co-doped trimodal-porous structured graphitic carbon electrocatalysts. Energy Environ. Sci. 2014, 7, 3720-3726. [CrossRef]

34. Yang, Z.; Xu, M.H.; Liu, Y.; He, F.J.; Gao, F.; Su, Y.J.; Wei, H.; Zhang, Y.F. Nitrogen-doped, carbon-rich, highly photoluminescent carbon dots from ammonium citrate. Nanoscale 2014, 6, 1890-1895. [CrossRef] [PubMed]

35. Patel, M.K.; Ali, M.A.; Krishnan, S.; Agrawal, V.V.; Al Kheraif, A.A.; Fouad, H.; Ansari, Z.A.; Ansari, S.G.; Malhotra, B.D. A label-free photoluminescence genosensor using nanostructured magnesium oxide for cholera detection. Sci. Rep. UK 2015, 5, 17384. [CrossRef] [PubMed]

36. Jeon, H.; Min, Y.J.; Ahn, S.H.; Hong, S.-M.; Shin, J.-S.; Kim, J.H.; Lee, K.B. Graft copolymer templated synthesis of mesoporous $\mathrm{MgO} / \mathrm{TiO}_{2}$ mixed oxide nanoparticles and their $\mathrm{CO}_{2}$ adsorption capacities. Colloids Surf. A Physicochem. Eng. Asp. 2012, 414, 75-81. [CrossRef]

37. Botha, A.; Strydom, C.A. DTA and FT-IR analysis of the rehydration of basic magnesium carbonate. J. Therm. Anal. Calorim. 2003, 71, 987-995. [CrossRef]

38. Ghanbari, D.; Salavati-Niasari, M.; Sabet, M. Preparation of flower-like magnesium hydroxide nanostructure and its influence on the thermal stability of poly vinyl acetate and poly vinyl alcohol. Compos. Part B Eng. 2013, 45, 550-555. [CrossRef]

39. Huang, J.Y.; Xu, M.Q.; Ge, Q.; Lin, M.H.; Lin, Q.; Chen, Y.H.; Chu, J.Y.; Dai, L.Z.; Zou, Y.S. Controlled synthesis of high-ortho-substitution phenol-formaldehyde resins. J. Appl. Polym. Sci. 2005, 97, 652-658. [CrossRef]

40. Wang, X.Q.; Liang, C.D.; Dai, S. Facile synthesis of ordered mesoporous carbons with high thermal stability by self-assembly of resorcinol-formaldehyde and block copolymers under highly acidic conditions. Langmuir 2008, 24, 7500-7505. [CrossRef] [PubMed]

41. Kim, W.J.; Yoo, J.C.; Hayhurst, D.T. Synthesis of hydrothermally stable MCM-41 with initial adjustment of $\mathrm{pH}$ and direct addition of NaF. Microporous Mesoporous Mat. 2000, 39, 177-186. [CrossRef]

42. Deng, Q.F.; Liu, L.; Lin, X.Z.; Du, G.H.; Liu, Y.P.; Yuan, Z.Y. Synthesis and $\mathrm{CO}_{2}$ capture properties of mesoporous carbon nitride materials. Chem. Eng. J. 2012, 203, 63-70. [CrossRef]

43. Verziu, M.; Cojocaru, B.; Hu, J.C.; Richards, R.; Ciuculescu, C.; Filip, P.; Parvulescu, V.I. Sunflower and rapeseed oil transesterification to biodiesel over different nanocrystalline $\mathrm{MgO}$ catalysts. Green Chem. 2008, 10, 373-381. [CrossRef]

44. Wickramaratne, N.P.; Jaroniec, M. Importance of small micropores in $\mathrm{CO}_{2}$ capture by phenolic resin-based activated carbon spheres. J. Mater. Chem. A 2013, 1, 112-116. [CrossRef]

(C) 2018 by the authors. Licensee MDPI, Basel, Switzerland. This article is an open access article distributed under the terms and conditions of the Creative Commons Attribution (CC BY) license (http://creativecommons.org/licenses/by/4.0/). 